\title{
THE EFFECT OF DIET UPON THE RESPONSE TO ORAL ANTICOAGULANTS
}

\author{
BY \\ H. PAYLING WRIGHT AND M. HAYDEN \\ From the Obstetric Unit, University College Hospital Medical School, London
}

(RECEIVED FOR PUblication AUgust 13, 1954)

\begin{abstract}
It is not uncommon in clinical practice to meet with patients who do not respond in the expected manner to the usual therapeutic doses of the oral anticoagulants. Some appear to be unusually sensitive, while others, who are encountered more frequently than these hyper-reactors, prove abnormally resistant to the action of these drugs. While carrying out clinical trials with "tromexan" (Burt, Payling Wright, and Kubik, 1949) and with " dindevan" (Payling Wright, 1954, in press) in groups of hospital patients with various thrombotic disorders, it was found that the proportion who manifested resistance was about one
\end{abstract} in six of those treated. The care of such patients furnishes some of the chief anxieties to the physician using anticoagulant drugs, for they may present difficulties of two distinct kinds. In the first, when the dose is increased in the effort to overcome the resistance, the drug may exhibit a cumulative effect, and occasionally a sudden, rapid, and full response occurs on the third or fourth day which depresses the prothrombin activity to such a degree that severe, spontaneous haemorrhage supervenes. In the second, at no stage is any satisfactory reduction of the prothrombin level achieved, so that much valuable time may be lost. In this group of patients the thrombus may enlarge during the period of ineffective treatment-a deterioration which naturally has a detrimental effect upon prognosis.

The causes of these variations in response to oral anticoagulants are not understood at the present time, and few observations of an experimental kind have been made which throw light on the nature of the response defect. Three questions may be posed: Is resistance due to failure of absorption from the gut, so that the drug never enters the blood stream? Is it due to failure of the coagulation mechanism within the body to be affected by the circulating anticoagulant? Or is it dependent upon fluctuations in concentrations of vitamin $\mathrm{K}$, which can modify the degree of hypoprothrombinaemia produced by a specific amount of anticoagulant ? Observations by Waldron, Beidelman, and Duncan (1951), Fullerton, Davie, and Anastasopoulos (1953), and recently by Duguid (1954) on the relationship of high fat in the diet to changes in the coagulation mechanism and the onset of intravascular thrombosis suggest that the diet, and especially the lipids, might, under certain circumstances, influence the response to oral anticoagulants. The following series of experiments was therefore undertaken in an attempt to elucidate the dietetic aspect of the problem and to try to answer the questions as to the nature of the failure of response in patients resistant to oral anticoagulant therapy.

\section{General Methods and Materials}

Young male albino rats, weighing between 150 and $250 \mathrm{~g}$., were used throughout the following experiments. Each group comprised not less than 50 animals, 25 receiving one of two special diets (vide infra). All other substances and drugs were administered by stomach tube while the animals were under light ether anaesthesia. Prothrombin estimations were carried out by the Quick single-stage technique, with thrombokinase (Geigy) as the thromboplastic source. Blood for these determinations was obtained by puncture of the vena cava while the animals were under deep nembutal anaesthesia. The anticoagulant used throughout was bis-3-3'-(4 oxycoumarinyl) ethyl acetate.* This anticoagulant, which is insoluble in neutral solution, was administered as a stable suspension prepared by grinding the active substance with $4 \%$ methyl ethyl cellulose in water. $\dagger$ The quantities were adjusted so that $0.75 \mathrm{ml}$. suspension contained $100 \mathrm{mg}$. " tromexan."

Two diets, listed in the table on the following page, together with water, were supplied to the animals in unrestricted amounts. During the observation periods no rat lost weight significantly.

" “Tromexan,” Pharmace ttical Laboratories, Geigy Ltd. + "Cellofas A," Imperial Che nical Industries, Ltd. 


\begin{tabular}{|c|c|c|c|}
\hline & & $\begin{array}{c}\text { High Fat } \\
\text { Diet A (g.) }\end{array}$ & $\begin{array}{c}\text { Low Fat } \\
\text { Diet B (g.) }\end{array}$ \\
\hline 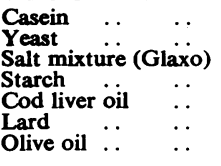 & $\begin{array}{l}\cdots \\
\cdots \\
\cdots \\
\cdots \\
\cdots \\
\cdots\end{array}$ & $\begin{array}{r}10 \\
5 \\
3 \\
51 \\
1 \\
30 \\
-\end{array}$ & $\begin{array}{r}10 \\
5 \\
3 \\
79 \\
1 \\
2\end{array}$ \\
\hline
\end{tabular}

In addition to these diets $0.5 \mathrm{ml}$. of a supplementary vitamin mixture was given daily by stomach tube to each rat. This mixture contained:

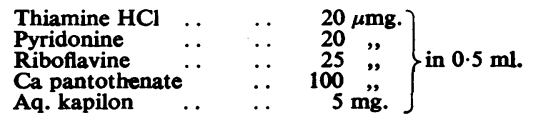

The techniques for each group of experiments, together with their results, will, for clarity, be set out separately.

\section{Group 1 : Effect of the Anticoagulant on the Blood Picture}

Batches of 25 rats of known weights were put upon one of the two diets, A or B, for one week. At the end of this period their red cell counts and haemoglobin percentages were determined on blood drawn by tail clip. Each animal then received $100 \mathrm{mg}$. $/ \mathrm{kg}$. body weight " tromexan " daily for five consecutive days by stomach tube. Under full anaesthesia, blood was withdrawn from the vena cava for further erythrocyte counts, haemoglobin, and estimation of mean corpuscular volume. On each day during the administration of anticoagulant, both faeces and urine were tested for the presence of blood; if detected, the animal was discarded. This precaution was taken, since occult blood loss would interfere with the interpretation of results.

Results.-The blood picture findings before and after five days' treatment with " tromexan " are set out below. The figures in brackets give the percentage change from the initial figure which took place during this period.

\begin{tabular}{c|c|c|c|c|c}
\hline & \multicolumn{2}{|c|}{$\begin{array}{c}\text { Red Cell Count } \\
(\mathrm{m} .)\end{array}$} & \multicolumn{2}{c|}{$\begin{array}{c}\text { Haemoglobin } \\
(\mathrm{g} . \%)\end{array}$} & $\begin{array}{c}\text { M.C.V. } \\
\text { (cu.u) }\end{array}$ \\
\cline { 2 - 3 } & Initial & Terminal & Initial & Terminal & Terminal \\
\hline Diet A & $7.15(100 \%)$ & $6.47(90 \%)$ & $13.9(100 \%$ & $12.0(86 \%)$ & 65.6 \\
" B & $6.96(100 \%)$ & $6.02(87 \%)$ & $13.7(100 \%)$ & $10.9(79 \%)$ & 66.4 \\
\hline
\end{tabular}

A small but definite fall in the erythrocyte count and haemoglobin percentage followed the administration of the anticoagulant, the effect being somewhat more marked in those animals kept on diet B. This trend was probably due to minor haemorrhages into the tissues, red cel's thus being lost to the circulation. Histological sections of liver, kidney, spleen, and bone marrow from으 animals on both diets demonstrated the presence $\Rightarrow$ of such haemorrhages, which were too small to $\stackrel{?}{?}$ be detected with the naked eye at necropsy. The kidney, and, to a lesser extent, the liver, were the chief sites of these haemorrhagic areas and, as $\frac{\bar{s}}{\bar{Q}}$ might be inferred from the changes in the peri- $\triangle$ pheral blood, were more frequently found in the rats fed on the low-fat diet. The normal corpuscular volume found after the administration of $\stackrel{\circ}{\circ}$ the anticoagulant offers further confirmation that $\vec{\omega}$ there is no change in the type of haemopoiesis? following its ingestion for a short period.

\section{Group 2 : Effect of Diets A and B on Prothrombin - Levels}

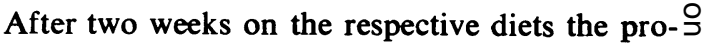
thrombin times of batches of rats were determined on vena caval blood to ascertain whether the $\mathbb{\Phi}$ regimen had any significant effect upon the coagulation mechanism. For control, prothrombin times of rats kept on the mixed diet provided in the stock breeding rooms, supplemented with green $\vec{\varphi}$ vegetables and milk, were used.

Results.-The effect upon the prothrombin times of the two d ets compared with normal controls was small. The high fat intake tended to depress the coagu'ation mechanism, an observation similar to those of other workers.

\begin{tabular}{|c|c|c|c|}
\hline & Controls & Diet A & Diet B \\
\hline $\begin{array}{l}\text { Prothrombin time (sec.) } \\
\text { Range (sec.) }\end{array}$ & $\begin{array}{c}14 \cdot 0 \\
13 \cdot 0-14 \cdot 5\end{array}$ & $\begin{array}{c}13 \cdot 6 \\
12 \cdot 5-14 \cdot 0\end{array}$ & $\begin{array}{c}14 \cdot 2 \\
13 \cdot 0-15 \cdot 0\end{array}$ \\
\hline
\end{tabular}

\section{Group 3 : Average Lethal Doses of Anticoagulant} for Rats on High- and Low-fat Diets

Further batches of rats were kept on the diets $\delta$ for one week, at the end of which time each received $100 \mathrm{mg}$. $/ \mathrm{kg}$. body weight " tromexan " daily윽 until death. From the group results, the average lethal dose for animals in each batch was obtained.

Results.-It was found that the average lethal $N$ dose for those animals maintained on diet A (high fat) was 1.182 g. " tromexan." That for animals 0 on diet B was almost half this amount, being only $\mathcal{\omega}$ $0.595 \mathrm{~g}$. It seemed, therefore, that the high-fat content of the diet had a saving effect for thece animals, fatal haemorrhage being more rapidly produced when fat was absent from the diet.

Group 4 : Effect of Single Dose of Anticoagulant in Rats on High- and Low-fat Diets

After one week on their respective diets the $\frac{?}{\mathbb{Q}}$ animals were given a single dose of $150 \mathrm{mg} . / \mathrm{kg}$. 
body weight "tromexan." Their prothrombin times were determined 24 hours later.

Results.-The effect of the anticoagulant, given on one occasion only, differed considerably in the two series. The average prothrombin time for rats on diet A was $18.54 \mathrm{sec}$., while that for those on diet B was $22.73 \mathrm{sec}$. The marked divergence in the responses demonstrates in a striking manner that the ingestion of fat protects the animals from the anticoagulant and reduces their hypoprothrombinaemic response, an observation already noted in a different form in Group 3.

\section{Group 5 : Effect of Antibiotic Sterilization of the Gut on Response to Anticoagulant}

In an attempt to disclose whether the variations in prothrombin activity observed in rats on the two diets were dependent upon alterations of vitamin $K$ concentration rather than on any inherent difference in response by the coagulation mechanism to the drug, each animal received chloromycetin* daily. It was hoped that the reduction of the intestinal flora brought about by the antibiotic would diminish the vitamin $K$ synthesis in the gut. Each animal, therefore, was maintained on one of the diets for one week; during the second week $400 \mathrm{mg}$. $/ \mathrm{kg}$. body weight chloromycetin was given daily in addition. On the fifteenth day $150 \mathrm{mg}$. $/ \mathrm{kg}$. " tromexan " was administered and 24 hours later the prothrombin time was determined as before. It must be noted that throughout the experimental period each animal daily received the vitamin mixture which contained water-soluble vitamin $K$.

Results.-Following the administration of the anticoagulant to animals receiving antibiotics, both series manifested a more pronounced hypoprothrombinaemia than was observed when they were kept on the diets only. The differences between those on diets A and B were, however, still apparent. The average prothrombin time for animals on diet A was $24.0 \mathrm{sec}$., while that for those on diet $B$ was $33.2 \mathrm{sec}$.

This difference between the results obtained in Groups 4 and 5 suggests that vitamin $K$ plays an important role in the response to the anticoagulant (Payling Wright, 1952). When the diet is high in carbohydrate, moreover, the sterilizing effect of the chloromycetin is more efficient than when the fat content is high. On diet $B$ the reduction of vitamin $\mathrm{K}$ was presumably greater ; the response to the anticoagulant was consequently uninhibited, and a pronounced hypoprothrombinaemia ensued.

\footnotetext{
- "Paediatric Chloromycetin Palmitate," Parke, Davis and Co., Ltd.
}

\section{Group 6 : Effect of Raising Bile-salt Content of Gut on Response to Anticoagulant}

Since one of the chief differences in the gut contents with diets of high- and low-fat constitution lies in the concentrations of available bile salts, it was possible that the discrepancies in prothrombin level observed between animals on the two diets might be dependent upon these steroids. With diet $\mathbf{A}$ it was possible that the bile salts might be fully utilized in ensuring fat digestion and that the full absorption of the anticoagulant might consequently be impaired. Such a condition might be rectified by the administration of bile salts before giving the anticoagulant.

After one week on the respective diets each rat daily received $100 \mathrm{mg} . / \mathrm{kg}$. bile salt in solution for a further week. On the fifteenth day $150 \mathrm{mg} . / \mathrm{kg}$. "tromexan" was given as before, and the prothrombin times were determined 24 hours later.

Results.-In this group the average prothrombin times for the animals on diets $A$ and $B$ were found to approximate more closely than in any of the other groups. The average time for those on diet A was $26.5 \mathrm{sec}$., while for those on diet B it was $28.6 \mathrm{sec}$. The presence of additional bile salts in the alimentary canal appeared to affect the response of animals on both diets. In this group the augmented response is therefore probably dependent upon an increased absorption from the gut, and the approximation of the findings in the two series suggests that those animals which receive a high-fat intake are less able to absorb the anticoagulant completely if the bile salt content is not augmented.

\section{Comment}

With the recognition of the importance of the absorption of vitamin $\mathbf{K}$ in modifying the response to oral anticoagulants of both man and experimental animals, it is strange that the circumstances which may alter conditions for its synthesis and absorption during anticoagulant therapy have not been more fully explored. Overman, Field, Baumann, and Link (1942) made suggestive and preliminary observations on rats, upon the effects of supplementing stock diets with alfalfa, fat, wheatgerm oil, choline, or vitamin C. They found that alfalfa, which is a rich source of vitamin $K$, was the only substance which altered the response of their animals to dicoumarol. In their experiments, however, the anticoagulant was mixed with the food so that an'mals which, for any reason, had a lowered appetite ingested less of the drug; the doses received by individual rats were thus 
undetermined. Though these workers reported that " additions of fat and choline to the basal diets did not materially alter the degree of hypoprothrombinaemia," they suggested that the slightly raised resistance to dicoumarol that they noticed with choline and fat might be due to large amounts of these lipid substances causing retardation of absorption of the drug from the gut.

During the present series of experiments it became apparent that when the diet contained large quantities of fat the anticoagulant was less effective in producing hypoprothrombinaemia. This result is not wholly explicable by alterations in the amount of vitamin $\mathrm{K}$ available, for all our animals daily received a supplement of the water-soluble form of the vitamin that sufficed for normal health. Moreover, the suppression of the synthesis of vitamin $\mathbf{K}$ by chloromycetin failed to abolish the difference between the prothrombin responses in animals maintained on the two diets. The effects of diet thus appeared to be independent of the vitamin available. It may be noted, however, that when the vitamin $\mathbf{K}$ was reduced with chloromycetin the prothrombin times of all animals, irrespective of their diets, were considerably prolonged-an observation that confirms that of Irving Wright (1952) for patients who received simultaneous anticoagulant and antibiotic therapy.

To what dietetic influence, then, could the differences in prothrombin times observed in our experiments be attributed ? From the findings in Group 6 it appears probable that the failure of the oral anticoagulants to produce a full response in animals results from its incomplete absorption. This partial failure is more evident in animals maintained on a high-fat intake, the high-lipid content of the gut retarding the absorption of the anticoagulant. When digestion of fats was improved by the oral administration of extra bile salts, the responses of the two series approximated, showing that the absorption of the "tromexan" in the presence of the two diets was now more nearly alike.

The problems posed in the introduction to this paper can only be partly answered by the results in the foregoing groups of experiments. First, the question whether differences in response to anticoagulants in patients undergoing treatment can be attributed to variations in the absorption of the drug from the gut. The results from animals that had received additional bile salts strongly suggest that the absorption factor may be of importance in determining the degree of response to a therapeutic dose of anticoagulant, for from our findings it appears probable that anticoagulant absorption may be impaired if the concentration of these $\frac{\text { - }}{-}$ steroids in the gut is too low. Secondly, the $\vec{F}$ question whether the coagulation mechanism fails to respond to absorbed anticoagulant cannot be directly answered. It is possible that our findings $\overline{\bar{n}}$. that a high-fat diet lessens mortality for rats may $\overrightarrow{\mathbb{D}}$ be interpreted as being partly dependent upon the lipaemic condition of the blood, a condition whiches is accompanied by a decreased clotting time $\vec{O}$ (Waldron et al., 1951 ; Fullerton et al., 1953). If the view of these two groups of workers that lipaemia entails an increased tendency to clot is admitted, this condition may be regarded as partially counteracting the effect of the anticoagu- $-\rightarrow$ lant; hence more of the drug is required to pro-is long the prothrombin time in the presence of ${ }_{\circ}^{G}$ lipaemia. Finally, the question of the importance of vitamin $K$ in modifying the response to $\vec{T}$ dicoumarol-like anticoagulants is again confirmed, $\mathscr{D}$ though it is doubtful whether fluctuations in response can be attributed to variations in the absorption of this vitamin.

In trying to assess the reasons for fluctuations, $\overrightarrow{\mathcal{H}}$ such as are met with in clinical practice in the responses of patients to oral anticoagulants, it is essential to realize that several interacting factors may operate simultaneously. Variations in diet, which alter absorption conditions in the gut, mayo of themselves be insufficient to influence the degree of hypoprothrombinaemia produced by a given $\overrightarrow{\hat{\sigma}}$ dose of anticoagulant, but when such a changes is accompanied by alterations in the gut of such a kind as to diminish the available vitamin $K \underset{\alpha}{0}$. far more profound change from the expecteक normal may follow the administration of the drug: Though it is not yet possible to analyse the effects of dietary change or of the metabolism of the in testinal bacteria on the coagulation mechanism? while the patient is under the influence of anticoagulants, it would appear advisable, from the foregoing experiments, to standardize within fairl $b$ narrow limits the fat intake of all cases receiving. these drugs, and to avoid, whenever possible, theif simultaneous administration with oral antibiotic or chemotherapeutic substances.

\section{REFERENCES}

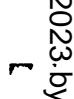
Burt, C. C., Wright, H. Payling, and Kubik, M. (1949). Brit. med. J

Duguid, J. B. (1954). Lancet, 1, 891.

Fullerton, H. W., Davie, W. J. A., and Anastasopoulos, G. (1953):

Brit. med. J., 2, 250. J. Nutrit., 23, 589 .

Waldron, J. M., Beidelman, B., and Duncan, G. G. (1951). Gastro. enterology, 17, 360.

Wright, H. Payling (1952). Lancet, 2, 1180.

Proc. Internat. Cong. Haematol., Paris, 1954. In the press. Wright, I. S. (1952). The Pathogenesis and Treatment of Thrombosis
p. 45. Grune and Stratton, New York. 